\title{
Why Silicon?
}

\author{
Michael J. Owen
}

Received: 20 November 2011 / Accepted: 29 November 2011 /Published online: 22 December 2011

(C) Springer Science+Business Media B.V. 2011

This journal is called SILICON but it might well have been named SILICIUM if this element's history had been slightly different or if this journal had been conceived in certain parts of Europe rather than in the United States.

Berzelius (1779-1848) was the great Swedish chemist, one of the founders of modern chemistry, who is credited with identifying the chemical element silicon in 1824 (he first isolated it the previous year). He called it Silicium, as the French, Germans, Dutch and Danes still do today. Despite its original Swedish name of silicium, a glance at a Swedish periodic table will show that our favorite element is known in Sweden today by a very different name - Kisel. Berzelius's isolation of elemental silicon resulted from his studies of silica and silicates. The scientific study of the constitution of silicates had begun earlier in the first decade of the nineteenth century when Berzelius, Smithson and Dobereiner simultaneously (1811) and independently concluded that silicates were salts of silicic acid or silica. Dobereiner (1780-1849) is perhaps better known for his contribution to the development of the periodic table - the Rule of Triads. Each of his triads was a group of three elements whose behavior was similar, e.g. Li, Na, $\mathrm{K}$ and $\mathrm{Cl}$, Br, I. Smithson (1764-1829), an English chemist and mineralogist, was the first to use the term "silicate". His posthumous legacy to the United States, a country he never set foot in, for "an establishment for the increase and diffusion of knowledge among men" resulted in the creation of the Smithsonian Institution in Washington DC. The mineral smithsonite is named after him.

\section{J. Owen $(\bowtie)$}

Michigan Molecular Institute, 1910 West Saint Andrews Road, Midland, MI 48640, USA

e-mail: michaelowen01@chartermi.net
The name "silicon" was coined in 1831 by the Scottish chemist and mineralogist Thomas Thomson (1773-1852) whose writings contributed to the acceptance of Dalton's atomic theory. Like Smithson, Thomson has a mineral, thomsonite, named in his honor. He felt that silicon had more in common with non-metals such as boron and carbon than it had with the numerous metals whose names end in "ium" (There were 26 such elements known to science in 1831, if you include aluminium rather than aluminum). Silicon is now generally recognized as a metalloid or semi-metal having characteristics of both metals and nonmetals so either version of the name would be acceptable or not depending on your point of view. Perhaps another different ending could be adopted to avoid choosing sides in this dualistic debate. Silicoid and siliconia come to mind as possibilities. The former is not as euphonious to my ear as the latter, but siliconia is probably a non-starter because of its potential mis-identification as an oxide rather than an element. In any event, both names are already claimed by others in entirely different contexts. My investigation on the web revealed that silicoid is an intriguing class of aliens. Siliconia, on the other hand, appears to be a collection of geographical regions.

The Silicoids (also known as The Swarm or Space Bees) turn out to be a silicon-based warrior race that is a major power in the Orion Sector. By virtue of their chemical constitution they are immune to pollution and hostile environments. Some commentators feel they are not really alive, but rather are drones gone wild. As for siliconia, the site tbtf.com/siliconia. $\mathrm{html}$ purports to be the definitive collection of names containing "silicon" in areas outside of Silicon Valley. Examples include: Cwm Silicon (Newport, South Wales), Silicon Alps (Carinthia, Austria), Silicon Bog (Ireland), Silicon Fen 
(Cambridge, England), Silicon Plateau (Bangalore, India), Silicon Polder (The Netherlands), Silicon Valais (Valais, Switzerland) and Silicon Wadi (Israel). With such a demonstrable world-wide acceptance of the term silicon, any move to change the name is clearly a lost cause. This is a pity because any name change would at least reduce the common confusion of silicon with the polymer silicone. Anyone doubting this confusion might care to "Google" an item such as silicon or silicone underwear. When I last checked, Google noted 7.6 million hits for "silicone underwear", half as many as the 15.2 million hits for the more unlikely "silicon underwear". 